\title{
АНАЛИЗ И ПРОБЛЕМАТИКА СДЕЛОК «СЛИЯНИЯ И ПОГЛОЩЕНИЯ» В РОССИЙСКОЙ ПРАКТИКЕ И ИХ ПРАВОВОГО ОБОСНОВАНИЯ, В ЧАСТНОСТИ, В СЕКТОРЕ ПРОИЗВОДСТВА НЕМАТЕРИАЛЬНЫХ АКТИВОВ
}

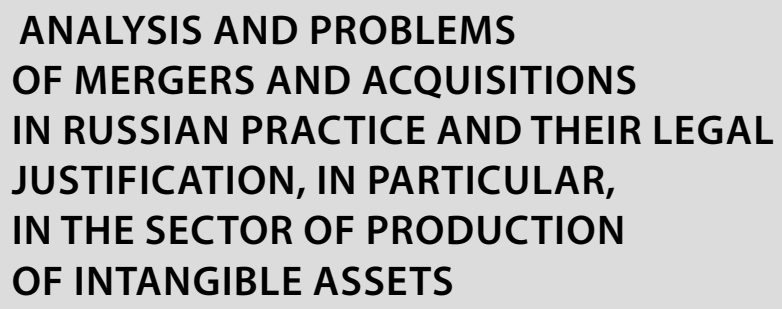

Summary. The article is devoted to the situation on the market of mergers and acquisitions. The relevance of the topic has greatly increased against the background of the global pandemic. But the article provides an analysis and highlights the problems of the Russian market. The legal lack of regulation of this issue in the Russian Federation leads to a very significant decrease in the value of assets in the implementation of such transactions, which is especially noticeable against the background of the fact that the Russian Federation is the leader among Eastern European countries in terms of their volume.

Keywords: corporate law, mergers and acquisitions, intangible assets.

\author{
Конотопова Елена Анатольевна \\ Московский университет имени С.Ю. Bumme, \\ 2. Москва \\ konotopova@gmail.com \\ Кирилин Алексей Владимирович \\ К.ю.н., дочент, Московский университет имени \\ С.Ю. Bumme, г. Москва
}

Аннотация. Статья посвящена ситуации на рынке слияний и поглощений. Актуальность темы очень возросла на фоне общемировой пандемии. Но в статье приведен анализ и освещена проблематика именно Российского рынка. Правовая незарегулированность данного вопроса в РФ приводит к весьма существенному снижению стоимости активов при осуществлении подобных сделок, что особенно заметно на фоне того, что Российская Федерация является лидером среди восточноевропейских стран по их объему.

Ключевые слова: корпоративное право, сделки слияния и поглощения, нематериальные активы.
H а данном этапе функционирования современного российского общества проведение общего анализа и выявление проблематики в сфере совершения сделок «слияния и поглощения» представляется наиболее актуальным, в связи с тем, что рассматриваемая сфера функционирует недостаточно четко и слажено в соотношении с зарубежным опытом реализации сделок «слияния и поглощения», однако, совершение сделок «слияния и поглощения» занимает важнейшую позицию для российских компаний.

Так, на сегодняшний день экономическое развитие и высокая конкурентная среда заставляют компании искать новые возможности для роста. Мировой опыт убедительно доказывает, что одним из самых действенных и эффективных путей формирования конкурентоспособных предприятий в нынешних условиях является концентрация капитала, которая обеспечивается через сделки слияния и поглощения. Нередко слияния или поглощения становятся единственным шансом вы- живания компаний. Поэтому количество таких сделок во всем мире неуклонно растет.

Мнения относительно состояния текущего российского рынка слияний и поглощений разнятся. С одной стороны, в целом деловая активность не очень высока в силу ряда причин (международные санкции, среднее качество инвестиционного климата, отсутствие большого количества хорошо развитых отраслей промышленности). С другой стороны, каждую неделю информация об этом и заметных сделках появляется в средствах массовой информации или становится известна из других источников.

Отметим, что рынок M\&A в каждой стране уникален и специфичен, что обусловлено различным уровнем экономического развития, состоянием финансовых рынков, развитостью законодательства и так далее. Российский рынок сложился относительно недавно и резко отличается от американского и европейского рынка. 
Характерная особенность российского рынка слияния/поглощения заключается в том, что относительно за небольшой период он быстро перешел от локальных сделок к крупным трансграничным сделкам. Следующей особенностью является то, что сделки M\&A в России, в основном, являются внутренними, заключаемые отечественными компаниями, а не зарубежными.

Данный факт обусловлен низким уровнем интереса зарубежных инвесторов к покупке российских активов. Однако со стороны российских компаний интерес к иностранным активам достаточно высокий.

В Российской Федерации холдингами, которые заключают сделки M\&A преимущественно с иностранными корпорациями, являются такие компании, как «Газпром» и «Лукойл», нацеленные на мировой рынок. Для российского рынка М\&А, как части мирового рынка, использование механизма слияния/поглощения становится неизбежным.

Согласно данным агентства Price Waterhouse Coppers Российская Федерация среди государств Восточной Европы является лидером по интеграционным процессам. Среди стран Центральной и Восточной Европы Россия занимает первое место по стоимостному и количественному объёму сделок по слиянию/поглощению.

Исходя из представленных данных можно отметить, что общая сумма сделок в 2019 году составила 7,4 млрд. долл. США- всего 53\% от объема первого полугодия 2018 года, что является вторым самым низким показателем за десять лет. Максимальную долю заняли сделки с участием ретейла (27\%) и ИТ-компаний (25\%). Сумма внутрироссийских сделок снизилась на $60 \%$, до 2,783 млрд. долл. США. Сумма сделок по покупке иностранцами российских компаний составила 2,392 млрд. долл. США - на 22\% ниже, чем в первом полугодии 2018 года. Сумма покупок российскими компаниями зарубежных оказалась на рекордно низком уровне с 1997 года, составив всего 7 млн. долл. США, падение по сравнению с первым полугодием 2018-го составило 99\%.

Однако в 2020 году, согласно отчету KPMG, резко изменилась ситуация на рынке компаний, работающих с нематериальными активами, что, по мнению ряда специалистов, знаменует, в частности, вступление РФ В новый этап структурного развития экономики и соответственно, порождает новые потребности правового регулирования сделок. Общие тренды 2020 г. отразились на М\&А-активности в российском секторе технологий, медиа и телекоммуникаций, которая стала еще более концентрированной. По итогам 2020 года можно выделить следующие тенденции:
- Продолжение тренда создания экосистем и размытия границ между секторами. На протяжении последних 2-3 лет многие крупные российские компании занимаются выстраиванием экосистем на стыке банковских и небанковских сервисов.

- Стремительное развитие E-commerce. Пандемия вызвала тектонические сдвиги на российском рынке E-commerce - сектора на стыке технологий и потребительских рынков. По оценкам экспертов, рынок е-commerce в 2020 г. вырос почти на $50 \%$.

- Всеобщий переход в онлайн. Пандемия ожидаемо спровоцировала стремительное развитие онлайн-сегмента во многих отраслях. Взрывной рост показал рынок EdTech - по оценкам экспертов, суммарная выручка Топ-50 крупнейших игроков рынка выросла почти в два раза относительно аналогичного периода прошлого года. Особенно высокими темпами растут компании, обучающие цифровым профессиям.

- Рекордные уровни оценки на международных рынках и мега успешное IPO Ozon. COVID-19 и последующий рост электронной торговли наряду с количественным смягчением привели к рекордным уровням оценки технологических компаний на публичных рынках.

Следует также отметить, что слияния и поглощения, осуществляемые в России, обладают рядом существенных отличий от данных процессов в странах с развитой рыночной экономикой. По результатам анализа слияний и поглощений компаний в России за последние несколько лет можно выделить основные характерные черты рынка $M \& A$.

Во-первых, здесь преобладают горизонтальные транзакции. Это означает, что во многих секторах происходит консолидация бизнеса. Эта тенденция ранее, в связи со структурными особенностями, относилась к нефтегазовой отрасли в России. Однако данные 2019-2020 годов показывают изменение отраслевой структуры. Интеграционные процессы все сильнее прослеживаются в телекоммуникационной и пищевой промышленности. В торговле идет процесс стремительной скупки региональных торговых сетей столичными компаниями.

Все более очевидно, что стратегии сделок, выбор горизонтального или вертикального варианта слияний, отличаются ярко выраженными отраслевыми особенностями. Абсолютными лидерами вертикальных слияний являются металлургические компании, которые продолжают строить вертикальные цепочки - от добычи руды до ее транспортировки конечному потребителю в лице иностранных компаний. А вот 
горизонтальные слияния характерны для торговли, телекоммуникационных отраслей, пищевой промышленности, за исключением высокоспециализированных секторов (виноделие, сыроварение, производство кормовых добавок) В последние годы основные новости о крупнейших сделках поступают из тех же секторов экономики, потенциал которых по-прежнему высок.

Одной из важных особенностей российского рынка слияний и поглощений является конфиденциальность информации. Большое количество мелких и средних сделок выполняется непублично, и не все данные о таких сделках поступают в СМИ. Зачастую участники рынка не знают ни имени покупателя, ни суммы сделки.

В условиях отечественного бизнеса нечеткость определения верхних уровней корпоративного управления продолжают оказывать негативное влияние на слияния и поглощения. Уязвимой областью остается несоблюдение прав различных групп акционеров. Таким образом, иностранные держатели ценных бумаг сталкиваются с серьезными юридическими барьерами при осуществлении своих прав. Следует, отметить, что в отличие от аналогичных практик зарубежных стран, иностранные держатели ценных бумаг и акций российских компаний редко используют инструментарий найма юридических компаний для представления своих интересов и защиты прав. Необходимо совершенствовать механизмы и процедуры внутреннего контроля с целью минимизации инвестиционных рисков. В то же время, если влияние акционеров на управление компанией превышает определенный уровень, это грозит минимизировать роль менеджмента и превратить его в чисто бюрократический придаток, что чревато повышением рисков и снижением экономической эффективности.

Для российских предприятий, которые в подавляющем большинстве обладают структурно более низким, по сравнению с зарубежными конкурентами, уровнем конкурентоспособности из-за отсутствия системы венчурного финансирования, большей дороговизны кредитных ресурсов, зачастую - нечетко сформулированной политикой господдержки, слияние может стать стратегическим фактором успеха для роста их рыночной стоимости, получение конкурентных преимуществ, укрепления собственных позиций на внутреннем рынке и завоевания новых рынков. Вместе с тем, процессы слияния и поглощения в России сдерживаются из-за наличия ряда проблем и препятствий, характерных для отечественного рынка М\&A. Основными из них являются:

1. экономическая нестабильность российских компаний в условиях замедления темпов роста национальной экономики, которая побуждает переносить заключение крупных сделок на неопределённые сроки;

2. нестабильное положение рынка слияний и поглощений, характерными чертами которого являются значительный уровень зависимости от проведения одноразовых крупных сделок, преобладающая ориентация на внутренние сделки и отказ от зарубежного инвестирования;

3. сокращение возможности привлечения заемных средств с целью финансирования сделок M\&A в силу различного рода санкций со стороны США и Евросоюза, что в свою очередь, приводит к увеличению рисков при кредитовании российских компаний и существенным изменениям режимов кредитования;

4. отсутствие действенной системы государственного регулирования сделок слияний и поглощений на российском рынке, разработанной применительно к различным секторам экономики с учетом реальных структур активов, сегодня бухгалтерско-финансовая система оценки активов не отражает реалии цифровой экономики, что приводит к формированию враждебных форм приобретения активов компаний на внутреннем рынке с применением мошеннических схем;

5. низкий уровень прозрачности деятельности российских компаний по сравнению с зарубежными, что может выступать в качестве фактора необоснованного завышения стоимости активов предприятия над стоимостью его бизнеса;

6. неэффективная, а зачастую - и несуществующая - система страхования рисков сделок слияния и поглощения;

7. «узость» рынка M\&A как по объемам заключенных сделок, так и по количеству участников. Это обусловлено нехваткой средств у внутренних инвесторов для совершения сделок; высокими политическими рисками, несовершенством законодательства в сфере защиты прав интеллектуальной собственности и отсутствием государственных институтов, которые эффективно защищали права владельца, являются основными препятствиями для внешних инвесторов.

8. несовершенство правового регулирования процессов слияния и поглощения в отечественной практике хозяйствования, в т.ч. отсутствие в отечественном конкурентном законодательстве регламентации понятий «поглощение», «рейдерство» и др.

Вышеуказанные проблемы осложняются несовершенством законодательных норм, устанавливающих ответственность за совершение незаконного присвоения объектов собственности и фактической невозможности государства противостоять этому явлению. 
Таблица 1. Крупнейшие сделки М\&А на российском рынке в 2019 г.

\begin{tabular}{|c|c|c|}
\hline Объект & Покупатель & $\begin{array}{l}\text { Сумма слелки, } \\
\text { марддозд. США }\end{array}$ \\
\hline Luxoft Holding Ine. & DXC Technology & 1,97 \\
\hline «Авито" ( $($ KEX еКоммерц $)$ & OKX Global B.V. & 1,16 \\
\hline «leнта» & «Cевергруші" & 0,65 \\
\hline «Лента» & «Cевергруші" & 0,6 \\
\hline «Ураткатиїь & Rinsoco Tranding Co Ltd. & 0,53 \\
\hline Рефтинская ГРЭС & «Кузбасэнергож & 0,37 \\
\hline «Лидер-Иивест” & Грушпа «Эталовь & 0,23 \\
\hline Групша «Эталонь & АФК аСистеман & 0.23 \\
\hline Завод жБалаково” АО „Северсталь” & $\begin{array}{c}\text { ООО «Абинский } \\
\text { электрометахтургический заводэ }\end{array}$ & 0,22 \\
\hline ПАО «Михайловский ГОК” & АО жЛебединский ГОК” & 0,2 \\
\hline
\end{tabular}

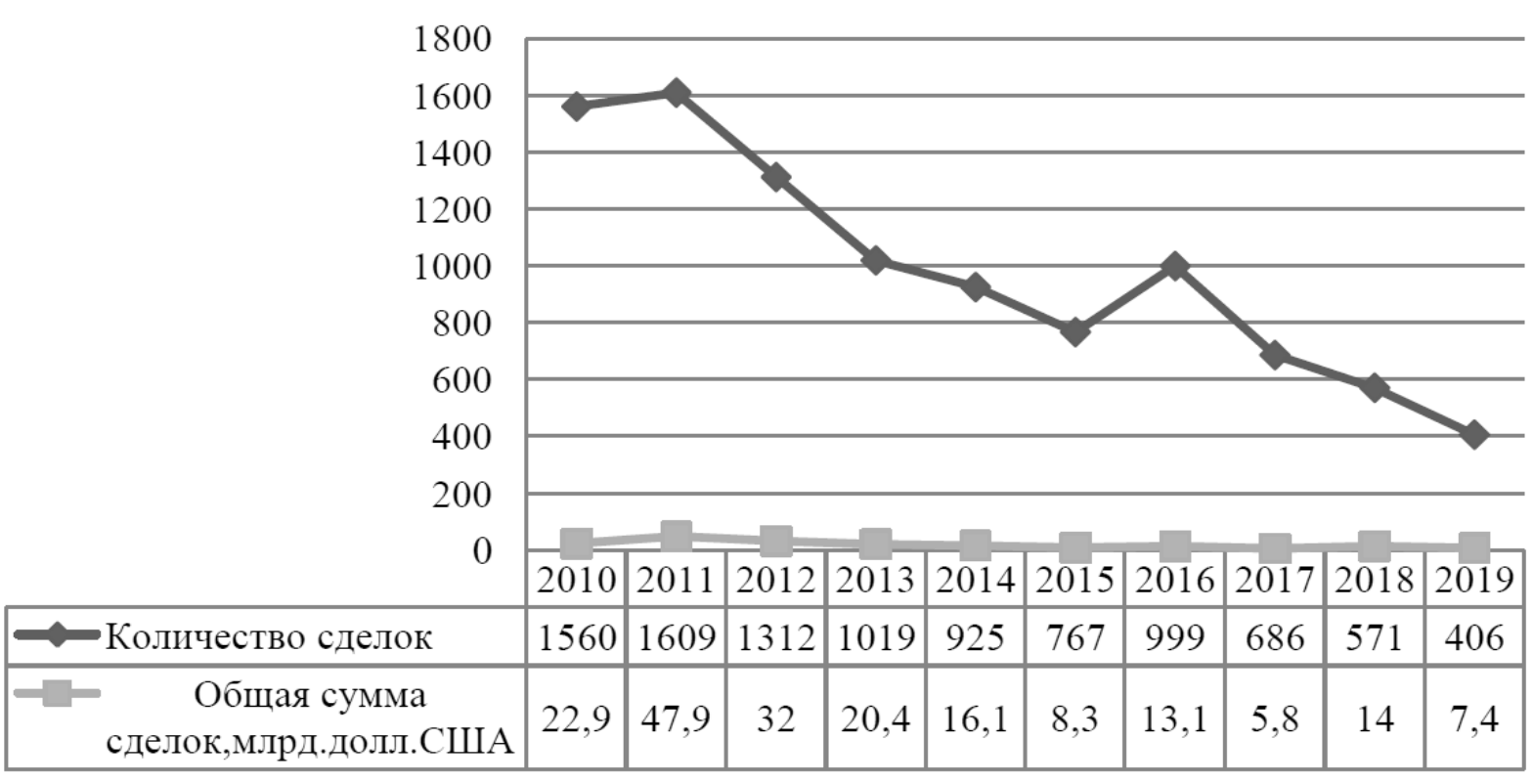

Рис. 1. Сделки по слиянию и поглощению с участием российских компаний за период с 2010 по 2019 гг.

Невзирая на отсутствие в России официальной статистики рейдерских атак, ученые, аналитики, эксперты, практики единодушны в том, что это явление негативно влияет на инвестиционную привлекательность страны, отпугивая не только стратегических иностранных инвесторов, но и внутренних. При этом проблема правового регулирования в данном случае приводит к необоснованному занижению рейтинга деловой привлекательности, так как дает возможность для распространения заведомо ложной негативной информации о защите собственности и коррупционной активности в РФ.

Анализируя российский рынок M\&A, следует отметить, что объем слияний и поглощений с участием российских компаний в первом полугодии 2019 года сократился на 47\% по сравнению с результатом первой половины прошлого года, отмечается в поступившем в РБК исследовании Refinitiv (бывшее подразделение F\&R Thomson Reuters).

Показатели сделок по слиянию и поглощению с участием российских компаний представлены на рисунке 1.

На сегодняшний день в России осуществляется ряд сделок слияния и поглощения, однако можно выделить 10 самых значительных сделок в 2019 году (Таблица 1).

С целью активизации процессов слияния и поглощения и повышение их эффективности в России необходимо решение следующих основных задач: 
1. обеспечение долгосрочного экономического роста и восстановления платежеспособного спроca;

2. повышение защиты прав собственности, в т.ч. и интеллектуальной, усиление уголовной ответственности за нарушение таких прав;

3. создание эффективной судебной системы применительно, в частности, к защите прав собственников;

4. системное развитие отечественного фондового рынка как реального инструмента привлечения средств для компаний и сделок по слиянию и поглощению;

5. усиление антимонопольного контроля в целях развития добросовестной конкуренции;

6. обеспечение прозрачности и информационной открытости слияний и поглощений на отечественном рынке;
7. законодательное ограничение возможности вторжения власти в бизнес, особенно на этапе реорганизации иными путями, кроме экономических;

8. усовершенствование нормативно-правовой базы, регламентирующих институт слияния и поглощения.

Таким образом, в результате проведенной работы был проведен анализ совершения сделок «слияния и поглощения» в Российской Федерации, было выявлено, что совершение таких сделок для российских компаний занимает приоритетное место в системе их функционирования и развития, однако, на данном этапе при реализации «слияния и поглощения» наблюдается значительная проблематика, при устранении которой совершение сделок «слияния и поглощения» сможет выйти на новый уровень, который успешно зарекомендовал себя в зарубежных странах.

\section{ЛИТЕРАТУРА}

1. Лучкина Д.В. Проблемы реализации сделок по слиянию и поглощению отечественных предприятий и пути их решения / Д.В. Лучкина // Научный электронный журнал Меридиан. — 2020.— № 8 (42). — С. 201-203.

2. Петрашова Л., старший партнер KРMG «Рынок слияний и поглощений в России в 2020 году» [Электронный ресурс] — режим доступа: https://home. kpmg/ru/ru/home/insights/2021/02/russian-2020-ma-overview.html (дата обращения 21.03.2021)

3. Попова М.С. Слияния и поглощения компаний в России / М.С. Попова // Russian Economic Bulletin. — 2020. Т. 3. — № 1.— C. 80-83.

4. Сперанский С.Н. Демографический аспект социально-экономического прогноза развития (на примере городского округа Иванова) / С.Н. Сперанский, М.А. Соловьева // Генезис экономических и социальных проблем субъектов рыночного хозяйства в России.— 2019.— № 13.— С. 119-122.

5. Сперанский С.Н. Основные проблемы повышения налога на добавленную стоимость в российской федерации / С.Н. Сперанский, Е.В. Куркина // Генезис экономических и социальных проблем субъектов рыночного хозяйства в России. — 2019.— № 13.— С. 122-124.

6. Хадырова 3.Б. Слияние и поглощение компаний в российской практике / 3.Б. Хадырова // Национальные экономические системы в контексте формирования глобального экономического пространства. Сборник научных трудов. - Симферополь, 2020. - С. 663-666.

7. Почему в России растает рынок слияний и поглощений [Электронный ресурс]. - Режим доступа: https://www.e-хесutive.ru (дата обращения: 20.08.2020).

8. Рынок слияний и поглощений [Электронный ресурс].— Режим доступа: http://mergers.akm.ru/ (дата обращения: 20.08.2020).

9. Состояние российского рынка слияний и поглощений [Электронный ресурс]. - Режим доступа: https://www.rbc.ru (дата 0бращения: 20.08.2020). 